\title{
The online game addiction, psychology and interpersonal relationship of the engineering students
}

\author{
Harits Ar Rosyid a,1,*, Della Murbarani Prawidya Murti a,2, Erna Fajariani ${ }^{\text {a,3 }}$, Hanif Adhilaga a,4, \\ Amalia ${ }^{\text {a,5 }}$ \\ ${ }^{a}$ Department of Electrical Engineering, Universitas Negeri Malang, Malang, Indonesia \\ ${ }^{1}$ harits.ar.ft@um.ac.id*; ${ }^{2}$ dellamurbarani4@gmail.com; ${ }^{3}$ ernarraini@gmail.com; ${ }^{4}$ adhilaga@gmail.com; ${ }^{5}$ amaliakakashi@gmail.com \\ * corresponding author
}

\begin{tabular}{|c|c|}
\hline ARTICLE INFO & ABSTRACT \\
\hline $\begin{array}{l}\text { Article history } \\
\text { Received October 10, } 2019 \\
\text { Revised October 31, 2019 } \\
\text { Accepted November 20, } 2019 \\
\text { Keywords } \\
\text { Online games } \\
\text { Students } \\
\text { Addiction } \\
\text { Psychology } \\
\text { Interpersonal relationships }\end{array}$ & $\begin{array}{l}\text { The trend of playing the online game had affected many kinds of people } \\
\text { including students. People play online games to relieve their tension or as a } \\
\text { mood repair, given that such games provide entertainment. This research aims } \\
\text { to determine the online game addiction of the students, their psychological } \\
\text { state, and also their interpersonal relationships. We collected data via a } \\
\text { questionnaire-based survey to } 72 \text { students who played an online game. From a } \\
\text { demographic perspective, most participants were male students from the } \\
\text { electrical engineering department. As a result, the indications of players' } \\
\text { addiction are the daily playing session of at least four hours and the fact that } \\
\text { they were experienced (loyal) players. Briefly, playing online games } \\
\text { contributed to the student's psychological state, emotional level, time } \\
\text { management, and also problem-solving ability. Fortunately, these players } \\
\text { rarely had conflicts with either their parents, friend or others. }\end{array}$ \\
\hline
\end{tabular}

This is an open access article under the CC-BY-SA license.

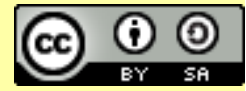

\section{Introduction}

Online game is a kind of game that can accessed by multiple players through a network synchronously or asynchronously [1]. Online game serves the purpose of entertainment for players, but it is potentially destructive as well. As such, can be originated from the strong (yet natural) motivation to become the best players, the pursue of collecting highly valuable items, or reaching game achievements. Often, these require players to play the game as often as possible to achieve their goals. The intensity of playing the game can also make the players addicted to the game [2]. They can become unaware of their surroundings due to the lacking interaction with their family and friends. These kind of players tend to isolate themselves from their community which later trigger psychiatric problems like depression [3]. Some experienced interpersonal relationship problems due to such antisocial-like behavior [4].

Many online game players are provoke-able, easily cursing, or saying bad words that negatively impact their social life. But one can prevent those negative effects from occurring through wellmanaged activities, relationship awareness, and also good game-playing ethic. As these things theoretically sound, this research opts to determine the online game addiction, the psychological state, and also the interpersonal relationship of the Engineering Students at the Universitas Negeri Malang. This research extends previous research that identifies the correlation between internet dependency on human's daily life [5]. 


\section{Method}

This research applied a survey method to a number of students from the Faculty of Engineering, Universitas Negeri Malang. With 72 students participated, 29 of them are Electrical Engineering students, 19 Mechanical Engineering students, 13 Civil Engineering students, and the remaining 11 students are from the Industrial Technology department. Male respondents were dominant in this survey by $72 \%$ of overall participants. It means only a mere 20 female students participated. This research activity was carried out within one month from 3 September 2018 to 5 October 2018. The place of this study is in the Faculty of Engineering, Universitas Negeri Malang.

Questionnaires are believed to be one of the most effective yet efficient way of a data collection method. It is a technique that allows respondents to convey their experience via a set of questions [6]. One of the advantages of using a questionnaire is the provided standard results to quantify certain aspects of the experience under consideration [7]. In addition, the questionnaire allows Online Game users to express their subjective experience even though in the parameters set by the items from the questionnaire [8], such as enjoyment [9], [10]. This questionnaire aims to analyze the addiction of playing online games, psychology and interpersonal relationships. The research questionnaire consisted of 33 questions wherein three questions are relevant to gaming addiction, 15 questions related to psychology and the remaining items are about participants' interpersonal relationships. There are four criteria used in this study, which are online games, online game addiction, psychology, and interpersonal relations.

The first criteria is an online games. One can define online games as games played via the Internet [11]. Unlike traditional PCs or game consoles where one or two players play games on a personal computer, online games allow many players around the world to play together on game servers over the Internet [12]. There are massive participating players at the same time, the online game's framework enables real-time communication via text-based or voice-based chat [13]. Majority players play online games to refresh or eliminating boredom both from daily activities (work, study, and other factors) and to fill up free time [14].

Next, the second criteria is online game addiction. Addiction to play online games is an example of Computer game Addiction indicated by excessive gaming routines [15]. One particular question is about the daily gaming duration in which affect their gaming experience. The indication is a frequent gaming for at least six months that potentially ruin their social and emotional life of the player[16]. Nowadays, one can find a cheap or even free internet connection to facilitate such the desire to play online games. A case study revealed the development of a bad mood or feeling uneasy when such online gaming addiction is not satisfied[17]. Online game players can spend most of their time just playing games while ignoring other important activities such as having meals, rehydrate or studying. Their dedication to achieving some multiplayer recognition sparks concern from colleagues. Teenagers are users suffering from this type of internet addiction. Teenage students spend at least two hours playing the online game.

The third criteria is psychology. Online game addiction is a Millenials' psychosocial problem, including students [18]. Children who have quality friendships have a low risk of game addiction, while children who have social anxiety and loneliness fall to the high-risk game addiction [19]. Also, feeling boredom to school activities in one of the internal motivators for students that drive themselves to play online games. As such is the anticipation of repairing a depression. In this study, there are psychological statements and terms often used by the players of online games such as "I become frustrated when not playing games". There is a degree of correlation between frustration and online game addiction [20].

And the last criteria is an interpersonal relationship. Interpersonal relationships happen when each other communicate or conveying messages, as well as forming relationships. It is constructed in various ways, one of which is online games. Most online games provide ways of communication between players [4]. However, the use of online games proved to be negatively correlated with interpersonal relationships [3], especially to non-gaming colleagues [21]. A player may have a good relationship with his/her in-game competitor or friends. On the contrary, players tend to have difficulty getting along with their family or school friends because they spent most of their time gaming rather than socializing. In this study, the statement used to measure the effect of online games on interpersonal relationships includes "I have had a fight with family or friends because I played online games", "I have neglected family or friends because I played too many online games". Game addicts 
are seldom to have physical or direct communication because they are getting used to interact in cyberspace. They prefer to recognize themselves in the virtual world. Thus, it makes them isolated from friends and family [22].

\section{Results and Discussion}

The result of the study is an analysis of the relationship between the indicators understudied. Such as the period of participants had known online games, the time spent playing online games, and where online gaming access influences the level of addiction. On average, male students had known games for more than one year compared to female students. The reason for female students playing online games is mostly to get rid of boredom. So, the intensity of the play is less than male students.

The gaming location also influences the length of gaming time. A comfortable, less-restricted, open access to wifi and the atmosphere of the environment can influence the choice of gaming place such as a boarding house or at home. Meanwhile, the campus becomes the alternatives place for gaming due to more academic activities. They are hence restricting their gaming time. The duration of playing online games is divided into three categories of gaming routines, which are two hours, four hours and more than four hours.

Players who access online games less or equal than two hours are familiar with online games for more than one year. Players utilize these routines to fill spare time and refreshing. In addition, female or male students who recognize games between one or six months do not prioritize games as their needs. In this category, players' interpersonal relationships are mostly fine, rarely experiencing conflicts with others and they can communicate well. Likewise, psychological health is good, because playing online games can reduce frustration levels, provide pleasure and maintain logical thinking.

The second category is players who access online games for four hours are nearly have the same characteristics as the previous category. However, there is a little occurrence of conflict between people. Fortunately, these players can manage their social life, can control their anger, and more manageable of their gaming time.

The last category is players who access online games for more than 4 hours. These players are similar to those of the categories above. But the longer the intensity of playing online games has worsened the interpersonal relationships and psychology of players. They often experience conflicts with parents, friends and other people. They experience difficulties in managing game time. Likewise, in psychological health, that is easily agitated, bad anger management, and anti-social behavior.

Table 1 shows the corresponding indicators of interpersonal relationships. The indicators measure the percentage of relationships with parents, friends, and others. Overall, responses reveal that gaming routines have little influence on interpersonal relationships.

In the psychological analysis of playing online games, there are psychological health, time management, and other indicators. Table 2 shows the resulting responses. Time management and Psychology are the highest psychological effects caused by online games on psychological health by 55 and 54 percent, respectively. Some examples of these psychological problems are stress, anger, boredom, and anxiety. In terms of time management in question, users often procrastinate work, lack of sleep and lacking attention to their health. While for other indicators such as uncontrolled expenditure due to online games and problem-solving habits, the percentage is $49 \%$.

Table.1 Interpersonal Relationships

\begin{tabular}{ccc}
\hline Indicator & Percentage & Information \\
\hline Relations with parents & $46 \%$ & Rarely has a conflict \\
\hline Relations with friend & $51 \%$ & Has been a conflict \\
\hline Relation with everybody & $41 \%$ & Rarely has a conflict \\
\hline
\end{tabular}


Table.2 Psychology

\begin{tabular}{ccc}
\hline Indicator & Percentage & Information \\
\hline Psychology & $54 \%$ & Often \\
\hline Time management & $55 \%$ & Often \\
\hline ,etc. & $49 \%$ & Rarely \\
\hline
\end{tabular}

In conclusion, online games have an ample degree of influence on the interpersonal and psychological relationships of the students in the Engineering Faculty of Universitas Negeri Malang. The addiction to playing online games is strongly influenced by several factors, such as the duration of recognizing the online games, the intensity of the gaming session and the place to access online games.

\section{Conclusion}

The results of the research conducted on 72 Engineering Students of Universitas Negeri Malang provide an overview of student addiction to online games, psychology, and interpersonal relationships. Male students dominated the participants of this study. In this study, there is a relationship between the availability of online gaming facilities and boredom experienced by students. When boredom arose, just slightly more than half of the respondents tend to play online games. These engineering students experience a stronger gaming addiction when they are at home or their boarding house because of the comfort and flexibility provided. Most of them play online games to fill their free time, as a mood repair or just to refresh their minds. The addiction of online games is strongly influenced by the interrelationship between several factors: the period of getting to know online games, the intensity of access, and location and facilities to access online games. Psychologically, online game addicts have caused bad time management such as procrastination and inconsistent sleep. Moreover, they often experiencing psychological instability such as stress, irritability, boredom, anxiety that detriment even more to the health of student's psychology. Fortunately, these engineering students rarely have issues in their interpersonal relations.

\section{References}

[1] J. S. Lemmens and S. J. Hendriks, "Addictive online games: Examining the relationship between game genres and Internet gaming disorder," Cyberpsychology, Behav. Soc. Netw., vol. 19, no. 4, pp. 270-276, 2016.

[2] E. J. Jeong and D. H. Kim, "Social Activities, Self-Efficacy, Game Attitudes, and Game Addiction," Cyberpsychol. Behav. Soc. Netw., vol. 14, no. 4, pp. 213-221, 2011.

[3] J. H. Kwon, C. S. Chung, and J. Lee, "The effects of escape from self and interpersonal relationship on the pathological use of internet games," Community Ment. Health J., vol. 47, no. 1, pp. 113-121, 2011.

[4] M. A. Liebert, S. Lo, D. Ph, C. Wang, and W. Fang, "Physical Interpersonal Relationships and Social Anxiety," Cyberpsychology Behav., vol. 8, no. 1, pp. 15-20, 2005.

[5] A. Kumazaki et al., "The Effects of Internet Use Psychological Health , Internet Dependency, Relationships lnterpersonal," pp. 17-27.

[6] A. I. Nordin, A. Denisova, and P. Cairns, "Too Many Questionnaires: Measuring Player Experience Whilst Playing Digital Games," Proc. Seventh York Dr. Symp. Comput. Sci. Electron., no. October 2014, pp. 6975, 2014.

[7] P. Cairns and A. L. Cox, "Research Methods for Human Computer Interaction,” p. 264, 2008.

[8] A. Adams and A. L. Cox, "Questionnaires, in-depth interviews and focus groups," Cairns, Paul Cox, Anna L. eds. Res. Methods Hum. Comput. Interact. Cambridge, UK Cambridge Univ. Press, pp. 17-34, 2008.

[9] H. A. Rosyid, M. Palmerlee, and K. Chen, "Deploying learning materials to game content for serious education game development: A case study," Entertain. Comput., vol. 26, no. 1, pp. 1-9, 2018.

[10]H. A. Rosyid, “Adaptive serious educational games using machine learning," University of Manchester, 2018. 
[11]R. Hilton, "Gaming as an education tool," Young Consumers, vol. 7, no. 2. pp. 14-19, 2006.

[12] J. Wu and D. Liu, "The effects of trust and enjoyment on intention to play online games," J. Electron. Commer. Res., vol. 8, no. 2, pp. 128-140, 2007.

[13]K. S. Young, "Understanding online gaming addiction and treatment issues for adolescents," The American Journal of Family Therapy, vol. 37, no. 5. pp. 355-372, 2009.

[14] S. Bigdeli and D. Kaufman, "Digital games in health professions education: Advantages, disadvantages, and game engagement factors," Med. J. Islam. Repub. Iran, vol. 31, p. 117, 2017.

[15]C. T. Wittek et al., "Prevalence and predictors of video game addiction: A study based on a national representative sample of gamers," Int. J. Ment. Health Addict., vol. 14, no. 5, pp. 672-686, 2016.

[16] J. S. Lemmens, P. M. Valkenburg, and J. Peter, "Development and validation of a game addiction scale for adolescents," Media Psychol., vol. 12, no. 1, pp. 77-95, 2009.

[17]R. S. Bimbingan and D. Konseling, "Ketergantungan Online Game Dan Penanganannya," J. Psikol. Pendidik. Konseling, vol. 1, no. 1, pp. 84-92, 2015.

[18]E. Pappa, F. S. Apergi, R. Ventouratou, M. Janikian, and I. N. Beratis, "Online Gaming Behavior And Psychosocial Well-Being in Greek Adolescents," Eur. J. Soc. Behav. Sci., vol. 15, no. 1, pp. 1988-1998, 2016.

[19] A. J. Van Rooij, T. M. Schoenmakers, A. A. Vermulst, R. J. Van Den Eijnden, and D. Van De Mheen, "Online video game addiction: identification of addicted adolescent gamers," Addict. Abingdon Engl., vol. 106, no. 1, pp. 205-212, 2011.

[20] A. M. Weinstein, "Computer and video game addiction - a comparison between game users and non-game users," Am. J. Drug Alcohol Abuse, vol. 36, no. 5, pp. 268-276, 2010.

[21] R. Punamäki, M. Wallenius, H. Hölttö, C. Nygård, and A. Rimpelä, "The associations between information and communication technology (ICT) and peer and parent relations in early adolescence," Int. J. Behav. Dev., vol. 33, no. 6, pp. 556-564, 2009.

[22] T. Greitemeyer and D. O. Mügge, "Video games do affect social outcomes: A meta-analytic review of the effects of violent and prosocial video game play," Personal. Soc. Psychol. Bull., vol. 40, no. 5, pp. 578589,2014 